\title{
Revista digital
}

Matemática, Educación e Internet

(http://tecdigital.tec.ac.cr/revistamatematica/).

Vol 18, No 1. Agosto - Febrero, 2018

ISSN $1659-0643$

\section{Relación entre cómic y enunciado matemático. Estudio y caso práctico}

\author{
José Luis González F. \\ Jluis.gonzalez@uclm.es \\ Facultad de Educación \\ Universidad de Castilla-La Mancha, España
}

Francisco Fernández de Simón Romero

fco.fernandezsimon@gmail.com

Colegio Ntra. Sra. Del Prado, España.

Resumen. El creciente fracaso escolar y la imagen antigua de las matemáticas entre los alumnos menos destacados obliga al sistema educativo a reformular el diseño de recursos didácticos. Entendemos que los alumnos de hoy reclaman material visual y desechan los enunciados de texto. Nuestra propuesta pretende unir imagen, texto y método didáctico a través del cómic. El resultado de nuestro trabajo son dos páginas con dos historias que adaptan dos capítulos de la novela El hombre que calculaba, escrita por Malba Tahan, con las que exponemos algunas pautas de lo que, pensamos, debería mostrar un cómic realizado para que lo utilicemos en el aula.

Palabras clave: cómic, enunciado, adaptación, fracaso escolar, diseño de recursos.

Abstract. The increasing school failure and the old image of the maths between the students oblige to the educational system to review the design of the didactic resources. We understand that ours students prefer visual material before text wording. Our proposal pretends to put together image, text and didactic methods through comic. The result of our work two pages with two stories that adapt two chapters of the novel The man who counted, by Malba Tahan. In these two pages has been exposed some patterns about how we think that a comic has to be used in class.

KeyWords: comic, wording, adaptation, school failure, design of resources. 


\subsection{Introducción}

El artículo que presentamos incluye el texto que contiene toda la información respecto a la investigación y resultados que hemos obtenido para nuestro trabajo.

Nuestro principal objetivo fue diseñar material didáctico que se distinga del material clásico para la enseñanza de las Matemáticas. Intentamos enfocar un tipo de acción educativa renovada y adecuada a las tendenciales educativas actuales que consideran esenciales cuestiones como el desarrollo de competencias y la transversalidad.

El enunciado con el que nos enseñaron matemáticas en nuestra etapa como estudiantes de Primaria se componía esencialmente de texto descriptor de una acción que, en muchas ocasiones, solo conseguía que el alumno se distanciara de su problemática y del proceso de resolución. De nuestra experiencia en las aulas, pensamos que la educación se ha convertido en un medio más visual aunque, por supuesto, no ha desechado al texto escrito. Por tanto, pensamos que un medio idóneo por el que enseñar matemáticas mediante la imagen y el texto puede ser el cómic y el arte secuencial debido a que se construye con imagen $y$, no necesariamente, con texto.

Para diseñar nuestro cómic buscamos información sobre los principales pioneros del arte secuencial, nombrados en el segundo punto, y cómo su evolución ha conseguido que este arte no aparezca como un simple entretenimiento sino como una herramienta útil para la acción educativa. Además, siguiendo a León (2104, p.117), se tuvieron en cuenta algunos de sus usos:

- Representar problemas matemáticos y su resolución.

- Presentar actividades lúdicas como juegos de ingenio y de lógica,

- Destacar errores que comúnmente cometen los estudiantes.

- Representar chistes matemáticos que pueden usarse como motivación o punto de partida para la reflexión sobre temas específicos.

\subsection{El cómic}

\subsubsection{Conceptos e historia del cómic}

El cómic, o arte secuencial, une literatura con narración gráfica siendo uno de los medios más expresivos de la cultura contemporánea. Su interpretación está condicionada por la experiencia individual, la memoria y el contexto, lo cual le confiere significados muy específicos que corresponden a convenciones culturales establecidas que permiten hablar de un lenguaje visual constituido por signos. Esos signos son estímulos que provocan una imagen mental evocativa y que se encuentra relacionada con otra. Hablamos del referente por semejanza o convención cultural, siendo así como se produce la comunicación visual. Charles Sanders Peirce, filósofo estadounidense de segunda mitad del siglo XIX, clasificó los signos según sus vínculos con el referente en símbolos, iconos e índices (Shirmahaleh, 2010). El símbolo se relaciona con un referente por convención y por experiencia cultural, mientras 
que los iconos se asemejan al estímulo que evocan y el índice tiene más conexión física con el objeto mencionado.

En el cómic, una sucesión de imágenes icónicas físicas puede convertirse en un relato en la medida en que se encuentren relacionadas entre sí, por características plásticas, simbólicas, formales y de contenido. El cómic no solo se compone de imágenes, sino que en la mayoría de ocasiones va acompañado de elementos escritos que confieren narratividad y sentido a la historia.

No se puede hablar de los inicios del cómic hasta que imagen y texto no fueron utilizados de forma integrada. Hasta ese momento, el texto sólo era un mero acompañante de la imagen, hasta que varios pioneros inventaron un medio que aunó imagen y texto de forma indivisible. Ellos fueron James J. Gillray, Rodolphe Töpffer, Wilhelm Busch o Las Aucas.

Hasta 1985 no hallamos el primer cómic de la historia tal y como lo entendemos hoy en día. Richard F. Outcault Outcault ideó el personaje The Yellow Kid y en sus viñetas, se encuentra la secuencia de imágenes consecutivas para articular un relato, la permanencia de al menos un personaje estable a lo largo de una serie y la integración del texto en la imagen. El éxito comercial de The Yellow Kid motivó al resto de diarios y prensa a incluir tiras cómicas en las páginas de los periódicos y conforme el consumo de tebeos y cómic se hizo mayor, los autores adaptaron sus historias para agradar al público. Nacieron de esta forma los géneros en el cómic, siendo los principales el policiaco, el de aventuras, el de superhéroes, o la novela gráfica. El cómic posee un carácter narrativo en su mensaje y debe integrar elementos verbales e icónicos utilizando una serie bien definida de códigos y convenciones. $\mathrm{Su}$ finalidad es predominantemente distractora pero las necesidades sociales y su propio prestigio han hecho que en múltiples ocasiones haya adquirido un rango instructivo. Su tamaño puede variar entre la tira cómica (de tres o cuatro viñetas), página, libro o álbum.

\subsubsection{Elementos básicos de un cómic}

Antes de que aparecieran los medios digitales, el tebeo era uno de los recursos más comunes para entretener a los niños y niñas. Hace fácil la comprensión de imagen y palabra y el tradicional desciframiento del texto. Gracias al cómic, aprender a leer no es sólo aprender a leer palabras sino también descifrar símbolos, información, integración y organización, es una actividad de percepción. Así, la lectura termina siendo un acto de doble vertiente ya que trabaja la percepción estética y la recreación intelectual exigiendo al lector de su facultad visual y verbal.

En la tira cómica o el comic-book de hoy en día, los elementos fundamentales son la viñeta, que separa y analiza las imágenes que conforman el enunciado total, y el bocadillo, que atrapa la representación del sonido y el habla, siendo útil para la descripción del tiempo.

Las viñetas sirven para indicar el paso del tiempo. Cada viñeta hace un análisis sobre lo visualmente cognoscitivo y perceptivo, alfabeto incluido, en el que el lector debe reconocer y llenar los vacíos de la acción que se producen entre viñeta y viñeta. Mediante la encapsulación de la imagen y la narración visual, la tarea del guionista y del dibujante registran un curso de experiencias mostrándolas tal como serían captadas por la vista del lector.

El recuadro de la viñeta compone parte del "lenguaje no verbal" del arte secuencial. La viñeta de líneas rectas suele mostrar una acción presente. El flashback (interrupción de la acción en curso para presentar los hechos que, ocurridos en un tiempo anterior, guardan relación con ella, Diccionario de la RAE), sin embargo, suele representarse con el recuadro alterado. Un recuadro ondulante es indicador 
de una acción pasada. Una viñeta sin recuadro hace alusión a un espacio ilimitado. En otro plano de análisis se encuentran la composición de la viñeta, la emoción, la acción, el decorado o la originalidad que deben utilizarse respetando el dibujo, la composición y la consecuencia narrativa combinando la emoción del dibujante con la capacidad visual e intelectual del lector.

La figura humana y el lenguaje corporal son otros de los ingredientes esenciales del arte del comic. La "lectura" de las posturas humanas o su gesto es una habilidad adquirida que poseen la mayoría de los seres humanos, en mayor grado de lo que ellos creen, desde la infancia ya que las posturas nos avisan de peligro o protección. Debemos distinguir entre gesto y postura (Eisner, 1996):

- Un gesto tiende a ser sutil y limitado entre una estrecha gama de movimientos que posteriormente el lector juzgará como adecuado o erróneo.

- Una postura es un movimiento seleccionado de entre todos los que constituyen una sola acción.

El gesto puede tener un significado más ambiguo. Para distinguir uno de otro acudimos a la cara y, en ella, a las cejas, los labios, la mandíbula, los párpados y las mejillas, todas responden a movimientos musculares que marcan la diferencia para comprender mejor lo que el dibujante quiere reflejar. Además, es la parte del cuerpo que más respalda a la palabra.

La concepción y composición escrita de la historia se ve afectada por las limitaciones del medio que dictan el campo de acción de la historia y la profundidad de la narración. Las historias y argumentos de acciones sencillas han dominado, desde hace mucho, la literatura de los comics, pudiendo tratar materias y temáticas complejas. Para ello, el dibujo se debe apoyar en el diálogo que da voz a los procesos del pensamiento y confiere significado a la acción, pero no hay manera de marcar una proporción de palabras-dibujos en un medio en el que las palabras (el rotulado) es parte de la forma. Es entonces cuando se recurre a lo visual, pues intenta emplear la mezcla de letra e imagen como un lenguaje con el que narrar ofreciendo al dibujante la oportunidad de describir un gesto o una escena que puede transmitir intensidad y una cierta dosis de emoción que el lector da por buena.

Existe una distinción en la temática y el objetivo del cómic a la que debemos hacer caso, ya que planteamos el uso del arte secuencial para una finalidad ajena al mero entretenimiento. Tal distinción separa el cómic de instrucción técnica del cómic instructivo de aptitudes. Un cómic puramente "técnico", o un cómic de instrucción técnica, ofrecen ilustraciones de procedimientos, métodos y modos de utilización, generalmente asociado con aspectos tales como montaje de aparatos o modo de repararlos. La ejecución de esas tareas es consecutiva y el éxito de este tipo de cómic como instrumento de enseñanza estriba en el hecho de que al lector no le cuesta entender lo que se le explica. Aquí, la disposición de las viñetas, la colocación de bocadillos o textos de apoyo cuidadosamente dispuestos en la página, está calculada para captar la atención del lector. Los cómics instructivos de aptitudes condicionan una actitud para un trabajo, la relación o identificación sugeridas en la interpretación o dramatización en una secuencia de dibujos es de por sí instructiva. Aprendemos por imitación y el lector, en este caso, puede suministrar fácilmente las acciones intermedias o conectivas echando mano de su propia experiencia.

Debemos tener esto en cuenta a la hora de diseñar o analizar un cómic con finalidades instructivas o como recurso educativo de las matemáticas. Así creemos necesario destacar de entre todas las herramientas disponibles para llevar a buen puerto el recurso educativo del cómic, los siguientes elementos (Eisner, 1996): 
- La máquina humana. El cuerpo humano (o animal) es un aparato mecánico con una gama limitada de movimientos y debemos comprender lo que puede hacer o no para su manejo.

- Perspectiva. Es la distancia, relación de una forma con otra, su configuración y su tamaño.

- Luz/Sombra. La luz procedente de su fuente aparece como un chorro de agua. La ausencia de luz es oscuridad. Un objeto que intercepta una corriente de luz es oscuro en el lado opuesto al que le da luz. Cualquier cosa o persona iluminadas por una misma luz arrojan una sombra sobre lo que tengan detrás, ya sea una pared, el suelo o cualquier otro objeto. Las sombras se acomodan a la superficie de la forma sobre la que caen. El uso de la luz causa un efecto emocional. Las sombras provocan miedo, mientras que la luz denota seguridad.

- Objetos. Suelen ser máquinas que van desde una sencilla caja vacía hasta un automóvil y todos tienen una anatomía y un alcance limitado de capacidad operativa.

- Mecanismos. El lector sabe que cada mecanismo tiene su funcionamiento y rechazará un dibujo incorrecto.

- Gravedad. Su utilización como artificio narrativo está muy extendida y todo el mundo lo entiende.

- Telas. La ropa sobre un objeto o llevada por una persona responde al tirón vertical de la gravedad y su respuesta a esa fuerza depende de la forma del objeto que lo sostiene.

- Caricatura. La caricatura es resultado de la exageración y la simplificación. El realismo es fidelidad a los detalles. La retención de los detalles confiere credibilidad, pues lo dibujado se parece mucho a lo que el lector ve cada día.

- Composición. Hay que considerar cada viñeta como un escenario donde tiene lugar una disposición de elementos que deben estar colocados según un propósito determinado. En una viñeta, nada debe ser accidental ni propio de un descuido. Se trata de enfocar el detalle o la acción más importantes, situándolos en el área de mayor atención.

- Bocadillos. Los diferentes tipos y usos de los bocadillos suponen en sí un abanico de posibilidades tan variado que el análisis de este sencillo elemento daría para un documento aparte.

- Lo visual vs. La ilustración. En los cómics, los dibujos son visuales. En los libros de texto, son ilustraciones. Lo visual sustituye al texto. La ilustración se limita sencillamente a repetir o ampliar, a decorar o a crear una atmósfera. Hay que recordar que el cometido del dibujante de cómic es el de dibujar y no el de ilustrar.

\subsection{El enunciado matemático}

En este artículo se presentan los atributos más representativos de un cómic típico, su relación con la matemática y una propuesta que articula de forma coherente el campo artístico con este campo de la ciencia. Pero no podemos avanzar hacia esa meta sin antes hacer una propuesta de lo que entendemos como enunciado matemático y nuestra opinión sobre los diferentes tipos de enunciados que podemos encontrar, así como su utilidad en la enseñanza.

Relación entre cómic y enunciado matemático. Estudio y caso práctico. José Luis González F. et al Derechos Reservados @ 2017 Revista digital Matemática, Educación e Internet (http://tecdigital.tec.ac.cr/revistamatematica/) 
Según Puig, un problema escolar de matemáticas es "una tarea de contenido matemático, cuyo enunciado es significativo para el alumno, que desea abordarla, pero que aún no ha producido significado" (en Deulofeu y Mallart, 2012, p. 83).

Para Díaz Rodríguez (1993), cada problema de matemáticas supone un proyecto personal que el alumno desea resolver y desarrollar, aunque no conozca el proceso por el que puede encontrar la solución inmediatamente, lo que exige construir el propio proceso recurriendo a conceptos, procedimientos o teorías matemáticas.

Callejo entiende el problema de matemáticas como "una situación planteada con finalidad educativa, que plantea una cuestión matemática cuyo método de solución no es inmediatamente accesible al alumno/resolutor que intenta resolverla, porque no dispone de un algoritmo que relacione los datos con la incógnita, o los datos con la conclusión, y por lo tanto, ha de buscar, investigar, establecer relaciones, implicarse emocionalmente, etc. para hacer frente a una situación nueva" (en Deulofeu y Mallart, 2012, p.84).

Carrillo (1996), Puig (1996) y Callejo (1998) entienden como problema matemático los juegos, pasatiempos o rompecabezas que necesitan procesos generales relevantes matemáticos para su resolución, aunque los conocimientos matemáticos implicados sean nulos, escasos o incluso escondidos.

Si queremos una clasificación acudiremos a Vila (2001) que diferencia los problemas matemáticos en ejercicios, cuestiones prácticas, problemas no contextualizados, situaciones problema y problemas de estrategia.

Éstas son las principales características de lo que entendemos por problema matemático:

- Utiliza diferentes procedimientos adecuados.

- Lo proponemos tanto fuera de la unidad didáctica, donde aparecen los procedimientos matemáticos que están implicados, como dentro de la unidad, pero en este caso necesitan más de un campo de procedimientos.

- En algunos las estrategias generales necesarias son más trascendentes en el proceso de resolución que los propios conocimientos matemáticos implicados.

- El proceso de resolución debe ser argumentado.

- Acostumbran a ser singulares y no forman parte de relaciones o listas de cuestiones, o si forman parte, no hay ningún tipo de relación entre ellos ni de contexto ni de contenidos.

- Los procesos y estrategias de tipo intelectual juegan un papel importante para su resolución.

Otra característica que se debería dar en la mayoría de las ocasiones es que debe poseer un componente lúdico, ya que una perspectiva más desenfadada ayuda a conseguir un mejor proceso de resolución y una empatía para con la materia. Algo que se ve refrendado por lo que afirman Deulofeu y Mallart (2012):

“... las recreaciones enfatizan la idea de reto que se esconde en la resolución de cualquier problema y permiten incidir sobre aspectos relacionados con la resolución de problemas, como las auto restricciones, las interpretaciones abusivas o las implícitas del lenguaje verbal que están tras los enunciados, 
las falsas intuiciones y las paradojas, las particularizaciones y generalizaciones y también la reflexión sobre los conceptos matemáticos presentes en el currículo y la práctica de procedimientos, tanto técnicas como estratégicas" (p. 85).

El proceso de resolución se divide en tres fases: abordaje, ataque y revisión. Para pasar de una fase a otra necesitamos un cambio de pensamiento sobre el problema que refleja, y saber si estamos logrando progreso o no. Igualmente se ha de dedicar el tiempo que sea necesario para aprender de la experiencia, revisando el razonamiento que posibilita llegar a la fase de ataque, que se aborda cuando el problema se plantea satisfactoriamente. La fase de abordaje es la que está dirigida a la comprensión del problema y la aclaración de los tipos de respuestas que se deben producir. Seleccionamos, repasamos y reponemos conocimientos antes de entrar en materia. Una vez hecho esto podremos pasar a la fase de "ataque". Creemos que es verdaderamente positivo convertir esta fase de abordaje en algo atractivo para que signifique un reto mayor. Un buen ejemplo son los ejercicios no estándar que cuentan con una gran aceptación entre los alumnos, muy superior a la de los de naturaleza estándar.

Ese atractivo es esencial para evitar hechos como el fracaso escolar, en el que intervienen numerosos factores, siendo el más común la falta de motivación (Lozano, 2003), por lo que entre las posibles soluciones a las que podríamos acudir para evitar el fracaso escolar está plantear una vida escolar más vinculada a la vida ordinaria y a los intereses del niño.

Acudimos al manejo del juego bien diseñado que permita solucionar el problema y adquirir buenas técnicas de aprendizaje. Los juegos fomentan las relaciones humanas ayudando a aceptar reglas y saber luego respetarlas. Potencian habilidades y estimulan el ingenio y no dejan su resolución al azar. Son una ayuda importante para que el alumno aprenda a saber perder sin angustia y a saber ganar con alegría. Todas estas ventajas del juego y su propuesta deben estar acorde con el trabajo en la Competencia Básica de Matemáticas. Pensamos que el aprendizaje basado en situaciones reales se convierte en efectivo y más placentero si permite una resolución de forma simbólica y ponen a prueba distintos procesos mentales.

El diseño de viñetas de cómic, las ilustraciones, las imágenes en general son los principales baluartes para adaptar las prácticas educativas con los intereses de las nuevas generaciones de alumnos que están acostumbrados al lenguaje plástico y visual por encima del textual. Así creemos que el uso del cómic representa una gran herramienta para la enseñanza de las matemáticas que todavía no ha sido utilizada en todo su potencial. 4 .

\subsection{Cómic y Matemáticas}

La relación que interesa entre cómic y matemáticas es aquella que aporte material con fines instructivos y no solo "entretenimiento" aunque no hemos encontrado muchos trabajos, viñetas o tiras cómicas cuya pretensión no fuera más allá que el de proyectar una broma. Desgranando conclusiones tras leer documentos y libros que han estudiado nuestro tema pensamos que las ventajas educativas son múltiples:

- Facilita al alumno el desarrollo de su capacidad analítica.

- Localiza elementos que definen los códigos cinéticos y sus distintos tipos. 
- Combina técnicas de trabajo en grupo, trabajo individual, crítico y creativo, y capacidad de expresión oral y escrita.

- El alumno está capacitado para producir cómic y no sólo consumir de historias. A este respecto expondremos nuestro punto de vista sobre el recurso tecnológico Pixton.com en el apartado que dedicaremos a la crítica de recursos bibliográficos y digitales que hemos encontrado.

- El niño adquiere códigos que van a acompañarle a lo largo de toda su vida.

- Crea hábitos de lectura.

- Enriquece las posibilidades comunicativas.

- Es vehículo de ejercicios de comprensión lectora.

- Es fuente de ejercicios que estimulan los métodos de análisis y síntesis.

- Desarrollo el pensamiento lógico del alumno.

- Se adapta a cualquier nivel y tema.

- Es eficaz para la superación de dificultades lecto-escritoras.

- Supone un camino corto y seguro hacia el libro.

No obstante, además de sus ventajas el cómic también cuenta con inconvenientes. Un mal uso haría que el alumno se lo tomara como un simple entretenimiento. Además, el alumno necesita conocer previamente el lenguaje particular del cómic antes de enfrentarse a su mensaje o empezará a focalizar su atención en los elementos que componen el cómic y no en el reto que le plantea.

Definir punto por punto los diferentes contenidos matemáticos expresados o utilizados para generar una tira o una historia sería algo demasiado por lo que nos limitaremos a reflexionar brevemente sobre la propia relación entre cómic y matemáticas. Algo difícil de abordar puesto que los diseñadores de cómic han empleado conocimientos matemáticos para predecir o explicar el comportamiento humano y social. El empleo de las matemáticas aporta diversas explicaciones racionales aceptables a las preguntas que le plantean la sociedad, la economía o la política.

En un estudio realizado por el Sistema Nacional de Medición y Educación del Aprendizaje (SINEA, 1998), para evaluar las competencias que poseían los discentes de las tres etapas, de la entonces, Educación Básica, se determinó que en el área de matemáticas los alumnos no lograban alcanzar los niveles de ejecución requeridos. El principal problema es la opacidad y sensación de ignorancia que generan las propias matemáticas, una sensación bastante extendida por la que encontramos personas que hablan mal de las matemáticas y no tienen pudor en reconocer que las suspendía o que no es capaz de abordar una sencilla cuenta casi sin sonrojo. Entre los muchos cómics, viñetas y tiras estudiados hemos encontrado algunos tópicos sociales respecto al papel de las matemáticas en la escuela y la sociedad. El profesor de matemáticas suele aparecer como alguien odiado, culpable para los padres, clásico. La asignatura de matemáticas aparece inútil, repelente y tediosa. Más aún si el tiempo de la acción está enmarcado en una época a la que el autor tiene poca simpatía. Por otra parte, la escuela aparece más asequible y alegre si el autor concibe ese tiempo como algo positivo. Eso debe cambiar promoviendo unas matemáticas más cercanas al alumno y al lector. 
Las matemáticas ya no son sólo el conocimiento de recursos, métodos y fórmulas de cálculo. Las matemáticas son también la competencia matemática. Ser competente es disponer de conocimientos, saber hacer, tener destrezas, y que repercutan en el ser, tener actitud de aplicar el conocimiento adecuado. Cuando un niño realiza una compra debe tener conocimientos y saber hasta qué punto llega su competencia como comprador. Los ilustradores son competentes matemáticamente a la hora de diseñar una viñeta y para presentar situaciones matemáticas y debemos aprovecharnos de lo que nos puedan enseñar y los recursos que nos puedan facilitar para la enseñanza. No solo las matemáticas deben servirse del cómic. Los creativos siempre han tenido en los símbolos matemáticos una herramienta para transformar en icónico un pensamiento abstracto. Las cifras y acotaciones, equis, fraccionarios $\mathrm{u}$ operaciones y signos han funcionado a la perfección como metáforas de lo que se quería contar. En el cómic, los chistes matemáticos parecen indicados sólo para los matemáticos pero las matemáticas aparecen en los chistes pero creemos que el humor gráfico es un recurso didáctico eficiente para la enseñanza de las matemáticas. El humor cuenta con tres funciones principales:

- Función intelectual: el humor ayuda a formarse conceptos matemáticos.

- Función afectiva: el humor facilita la comunicación y permite crear un clima agradable en la clase.

- Función pedagógica: el humor ayuda en la relación didáctica ya que nos da la ocasión de presentar situaciones en las que los conceptos matemáticos tienen sentido.

También utilizamos el humor para que los alumnos se relacionen con vocabulario, conceptos, errores habituales, representaciones frecuentes, etc. Otros usos serían la realización de carteles humorísticos para el aula o inventar chistes para aprender matemáticas buscando abandonar esa imagen tan tétrica de las matemáticas pudiendo conseguir una enseñanza-aprendizaje más útil y entretenida.

\subsection{El Hombre que calculaba. Análisis de Recursos}

El hombre que calculaba, publicado en 1938, se traducido a más de 12 idiomas, incluyendo inglés y español. El libro cuenta las aventuras de Beremiz Samir, un hombre con gran habilidad para los cálculos que resolvía problemas y situaciones complicadas con el uso de las matemáticas. Esta obra es al mismo tiempo una novela y un libro de problemas y curiosidades matemáticas.

Uno de los capítulos más famosos es el tercero, cuya sinopsis expondremos en el apartado siguiente puesto que es uno de los que vamos a adaptar en nuestro cómic. Hemos buscado adaptaciones hechas para blogs y vídeos con animaciones y son poquísimas las que nos han parecido interesantes y vistosas. La mayoría cuentan con un dibujo que nos parece feo, son demasiado largas o están narradas con un sistema de audio de poca calidad que no consigue distraernos. Solo hay un vídeo que nos haya llamado la atención si bien dudamos que pueda ser utilizado de forma eficaz en un aula. El hombre que calculaba, subido a youtube. es desde el directorio del usuario conocido como "Chanchullo", es un fotomontaje animado que desarrolla a la perfección la trama del capítulo y explica de forma efectiva el problema matemático que plantea. Nos ha gustado la cantidad de recursos pop que utiliza con referencias a Chuck Berry, Marilyn Monroe, Batman y el videojuego Street Fighter II. Si nuestros alumnos conocen varias de esas referencias puede ser un divertido recurso que no se hace largo, puesto que la duración del vídeo es de 3:44 minutos. Si no es así tal vez muchos de los chistes se diluyan. No obstante, el vídeo 
explica correctamente todo el problema que el capítulo de la novela de Malba Tahan plantea.

Hemos encontrado varias propuestas de actividades que combinan la enseñanza con el cómic pero dirigidas a otras materias. Otros combinaban cómic y matemáticas pero han terminado siendo desechados ya que el espacio web que hacía de fuente no nos daba impresión de seriedad o la propuesta no estaba lo suficientemente clara o su diseño era malo. Tras algunos intentos de localizar propuestas interesantes, llegamos al directorio del usuario de youtube.com "Antonio Martín 2020". Investigando el perfil del usuario solo podemos dirimir que su intención es compartir vídeos divulgativos de la enseñanza de las matemáticas y su pretensión es investigar y experimentar con recursos matemáticos. Su catálogo de vídeos subidos al directorio de youtube. com es amplio y variado, pero es uno de esos vídeos el que más nos interesa. Tal vídeo tiene el título "III.4.26. MARCOS MARRERO: Lengua y matemáticas EL CÓMIC" y su duración es de 6:04 minutos. Está grabado con una videocámara o con la cámara de un teléfono móvil de forma amateur. En él, encontramos al que debe ser Marcos Marrero, puesto que en el vídeo es llamado varias veces como Marcos, presentando dos posibles actividades para trabajar en el aula con las matemáticas y el cómic.

La primera plantea un cómic de cuatro viñetas con dibujos y texto que cuentan las historia de tres niños que van al cine. El cómic aporta el dato del dinero en total que se han gastado y el precio de las entradas del cine pero no el precio del bol de cotufas (palomitas de maíz). La intención del cómic es resolver una simple resta y división para hallar el valor del bol de cotufas. El comic utiliza unos dibujos diseñados mediante algún programa informático, su tipografía es digital y, por su tamaño, los dibujos y textos son fáciles de entender. Sin embargo, pensamos que el diseño de estas cuatro viñetas resulta demasiado trabajoso para tan poco rendimiento académico como el que requiere. Bien es cierto que los dibujos son obtenidos por medios que facilitan su incorporación al cómic, como por ejemplo Google.es/imágenes, pero siempre deberán condicionarse los contenidos a las imágenes que pueda ofrecer.

La segunda propuesta que Marcos Marrero nos hace en el vídeo es un nuevo cómic, de cuatro viñetas de las que tres están totalmente en blanco y la última posee el dibujo de una bicicleta acompañada de un bocadillo estrellado en el que leemos "125€". Marrero propone en esta ocasión completar el cómic para explicar esa última viñeta y ese valor de 125 euros. Pensamos que, si la primera idea mostraba demasiado trabajo para el profesor, en este caso nos parece que la actividad peca de dejadez. Además, que el alumno encuentre una referencia de partida matemática no significa que vaya a rellenar el resto de las viñetas con material matemático.

Pensamos que ambas propuestas poseen una muy buena intención, y ante alumnos interesados en la materia, serán muy útiles, pero no creemos que sean indispensables para trabajar con el cómic y las matemáticas.

Otro medio interesante para nuestro cometido es el espacio web y aplicación para dispositivos IOS y Android llamado Pixton.com. Es un recurso digital online basado en el Click-n-Drag Comics, tecnología patentada para crear comics. Permite crear tus propios personajes, características, posturas y bocadillos. Sus creadores fueron el matrimonio Clive y Daina Goodinson, residentes en Parksville, en el estado de Columbia Británica, Canadá. La web ha ganado varios premios por su aportación innovadora Permite tres opciones: Pixton para divertirse, Pixton para escuelas y Pixton para negocios. 
Pixton para divertirse es una opción gratuita que pone a disposición del usuario las opciones básicas para realizar un comic en el espacio web. El número de viñetas y de caracteres es limitado y sólo permite modificar al propietario de la cuenta que debe ser creada. Pixton para escuelas es una modalidad de pago que abre considerablemente las posibilidades de uso. Aparte de una mayor disponibilidad de viñetas y caracteres, permite la creación de un aula en el que la cuenta creada con el rol de "maestro" posibilita el control del trabajo que diferentes usuarios pueden hacer sobre un mismo cómic, modificando e incorporando aspectos, y que actúan con el rol de "estudiantes". Las herramientas a disposición del usuario son muy fáciles de utilizar y un recurso educativo apropiado para cualquier edad. Ante la falta de relación con el objetivo de este trabajo ni del uso principal que queremos hacer de este recurso hemos decidido obviar la opción Pixton para negocios. Nuestra experiencia ha consistido en la experimentación con diferentes herramientas y recursos que ofrece Pixton. com para diseñar algunas viñetas sin trama lógica alguna y sin publicación. No hemos realizado un análisis pormenorizado de los servicios que ofrece a la hora de interactuar con otros usuarios o de estudiar la relevancia de los trabajos que pudiéramos colgar en la comunidad Pixton. Así pues, con los ejercicios realizados y comparando los resultados iniciales con un trabajo de comic elaborado de manera artesanal distinguimos varias conclusiones, tanto positivas como negativas.

En el aspecto positivo, permite diseñar y crear viñetas, diálogos y argumentos característicos de arte secuencial aunque el usuario no tenga habilidades en el dibujo. Pixton también facilita cambiar ágilmente la composición plástica para comparar y elegir el diseño más adecuado. Para alumnos de Primaria, la modificación de los elementos que aparecen en una viñeta como el acercamiento o alejamiento de un paisaje montañoso muestra cómo las matemáticas condicionan el tamaño, la perspectiva, la simetría y las proporciones de los caracteres.

En el aspecto negativo cabe destacar que no genera arte. El diseño de personajes, entorno y complementos es objetivo. El resultado final no distingue usuarios salvo en el gusto y las opciones elegidas para detalles como la vestimenta o el atrezo de fondo. La línea del dibujo siempre es un trazo negro de grosor variable pero perfecto. Los colores siempre aparecen planos y sin matices. Si un usuario quiere hacer un uso de Pixton no encontrará un rasgo identificativo de su gusto creativo.

En definitiva, Pixton.com funciona como herramienta para crear cómic por usuarios no iniciados o que no tengan pretensiones artísticas pero que dejará frío a quien pretenda transmitir emoción y elaboración.

\subsection{Análisis de elementos usados para realizar el cómic.}

Nuestra pretensión es la de elaborar un cómic para utilizarlo como recurso educativo para la enseñanza de las matemáticas. Para ello, hemos estudiado los orígenes del medio del arte secuencial y los elementos básicos que lo componen. Hemos definido si un trabajo de este tipo sería óptimo o no para nuestro cometido llegando a la conclusión de que es adecuado y necesario. Hemos analizado las propuestas que otros especialistas han presentado observando la diversidad de trabajos que ya se han hecho previamente al nuestro. Hemos investigado recursos TIC. Ahora toca explicar nuestra propuesta y las decisiones que hemos tomado acudiendo a todo lo aprendido. 
Para la elaboración de nuestro cómic proponemos dos capítulos de la novela El Hombre que calculaba, escrita por Malba Tahan. Realizaremos una breve versión de dos de sus capítulos más populares. Son los siguientes:

Capítulo III. Donde se narra la singular aventura de los treinta y cinco camellos que tenían que ser repartidos entre los humanos "árabes". Cómo Beremiz Samir, el Hombre que Calculaba, efectuó un reparto que parecía imposible, dejando plenamente satisfechos a los tres querellantes. El lucro inesperado que obtuvimos con la transacción.

Los dos personajes protagonistas se encuentran a tres hermanos con el problema de reparto de la herencia de su padre, de treinta y cinco camellos, correspondiendo al mayor la mitad de la herencia, al segundo una tercera parte y al tercero una novena parte. La división no da un resultado perfecto lo que provocará la discusión. El problema se soluciona con una estrategia utilizada por Beremiz Samir que deja satisfechas a todas las partes.

Hemos tomado algunas licencias que facilitarán la elaboración del trabajo y no obligan a realizar una historia demasiado larga para el alumno. La finalidad del cómic es atraer al alumno hacia las matemáticas y no ser un trabajo de diseño artístico extenso. Así, hemos reducido la historia a una página y 7 viñetas de las que dos no cuentan con texto pero sí con símbolos numéricos que aporten información. Presentamos algunas viñetas sin marco si bien el texto que acompaña a esas viñetas sí aparece encuadrado. Otro detalle obviado es el contexto de la acción. Sólo la última viñeta da alguna sensación de un entorno desértico pero marcado sólo con algunas líneas en ese último dibujo porque nos convenía para la composición estructural. De no haber hecho esto, el momento hubiera quedado un tanto vacío.

El diseño de los caracteres posee estilo cartoon y no realista puesto que implicaría más tiempo de elaboración y páginas de desarrollo que nos obligarían a dibujar viñetas más grandes en donde pudieran quedar los detalles del dibujo más a la vista. Cada viñeta se muestra en blanco y negro y con un dibujo dominado por la línea. La masa de negro prácticamente no existe. Hemos desechado el color por encontrarlo irrelevante para la información que queremos ofrecer. Al no incluir color ganamos tiempo de elaboración y evitamos desviar la atención del problema matemático que nos interesa proponer.

El guión también es esquemático, lo cual no lleva a que el problema este insuficientemente planteado. De hecho, esa es una de las licencias más importantes que nos hemos tomado. En el texto original, el problema del reparto de los 35 camellos queda resuelto. Sin embargo, nosotros pedimos su resolución y confirmación al alumno. No dejamos espacio para que escriba la solución o realice apuntes por lo que la ficha será utilizada tantas veces como se quiera sin necesidad de hacer copias. También hemos renombrado la historia cambiando el nombre original del capítulo de la novela por un sencillo La Herencia y bautizado al camello del protagonista con el nombre de Rodolfo.

Capítulo XVI. Dónde se cuenta la famosa leyenda sobre el origen del juego del ajedrez, que Beremiz Samir, el Hombre que Calculaba, narra al Califa de Bagdad, Al-Motacén Billah, emir de los Creyentes.

El capítulo cuenta la relación de Bremiz Samir con un rey tras enseñarle el juego del ajedrez y la recompensa que nuestro protagonista pide por el favor realizado. La conclusión de esta historia es sorprendente y ofrece una perspectiva diferente a la que tenemos del tablero de ajedrez. 
Hemos dividido la página en seis viñetas del mismo tamaño pero sin encuadre. La referencia para diferenciar viñetas está en los bocadillos de narración, con texto en primera persona. Es el protagonista quien nos habla aunque nunca le vemos ni sabemos realmente quién es. Los bocadillos de narración no están colocados a la misma altura sino que la hilera de las viñetas de la izquierda lo tiene colocado en su extremo superior y la hilera de viñetas derecha lo tiene en el extremo inferior. Esto ha supuesto un error grave de estructura porque la narración es legible pero el organigrama de dibujos queda desequilibrado. Cierto es que lo más importante es la narración y no los dibujos, pero aun así no podemos negar que la composición resulta extraña al ojo.

Los caracteres de esta página son el Rey y el Tesorero real. Hemos dibujado el tablero de ajedrez en dos viñetas como elemento principal icónico. Dibujo blanco y línea negra por encima de la masa de tinta y cartoon esquemático son, de nuevo, las principales características del diseño.

Para utilizarla como recurso didáctico hemos dejado la historia en suspense y el alumno deberá hacer la operación que ha hecho el tesorero real y que nosotros no especificamos en el cómic. Suponemos que la historia generará un interés en el alumno, de lo contrario supondría un completo fracaso ya que hemos sacrificado la riqueza narrativa de capítulo de la novela original a fin de obtener un resultado de una página más accesible y aunque nosotros conocemos el desenlace de la trama preferimos crear expectativas para que el alumno de atreva a buscar la clave por sí mismo.

\subsection{El resultado.}
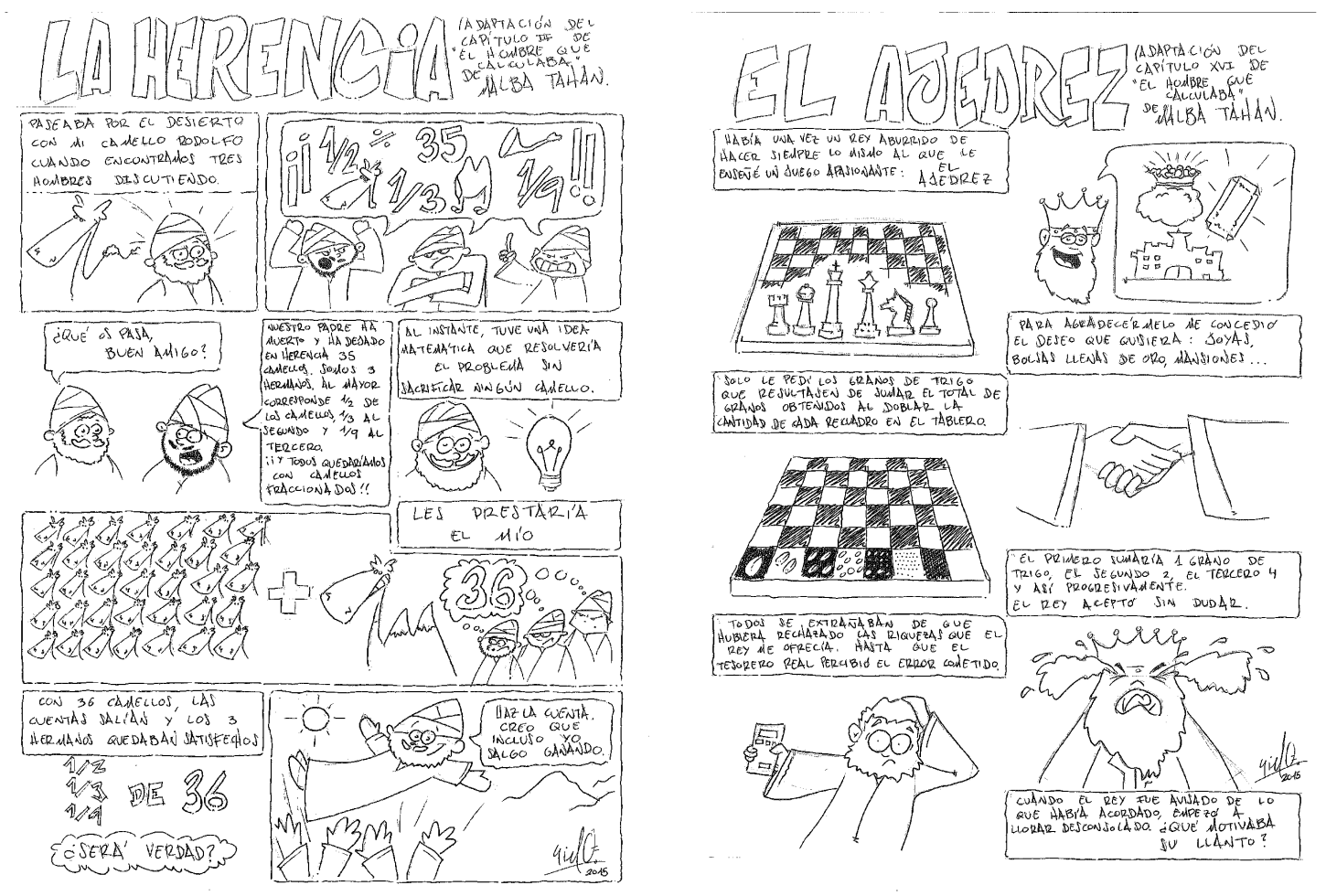


\subsection{Conclusiones.}

A continuación, pasamos a exponer las conclusiones extraídas del trabajo que se ha desarrollado:

- El cómic permite trabajar transversalmente con áreas como la Lengua y la

- Educación Plástica por la inclusión elementos de éstas.

- Es una labor atractiva para el profesorado aficionado al cómic.

- Para diseñar este material no es necesario saber dibujar ya que existen recursos digitales que posibilitan el buen fin de la tarea.

- La idea y el guion deben prevalecer sobre el dibujo en el planteamiento de problemas matemáticos. Un buen dibujo es esencial, pero éste no tiene obligatoriamente que ser perfeccionista y elaborado. Un dibujo esquemático puede ayudar a alcanzar los objetivos planteados.

- Este tipo de material requiere realizarse con paciencia. Es conveniente que aprovechemos cada imagen o página para trabajar el máximo contenido posible y no solo con las operaciones más sencillas.

- Debemos presentar todo este material a los alumnos como si de un juego se tratase. Mostramos así unas matemáticas lúdicas y dinámicas que acaben con los prejuicios asociados a esta materia como algo únicamente formal y distante.

- Una composición experimental de las viñetas puede distraer al alumno-lector, conviene no arriesgar a fin de hacer el problema matemático más comprensible.

Se recomienda implementar este material en el aula, aspecto importante para indagar el efecto que produce el material elaborado.

\section{Bibliografía}

[1] Alsina, A. Desarrollo de las Competencias Matemáticas con recursos Lúdico-Manipulativos, para niños y niñas de 6 a 12 años. Narcea, Madrid. 2004.

[2] Bujanda, M. P., de la Fuente, A. M. Juego y aprendo. Matemáticas. De 11 años en adelante. Organismos oficiales, Madrid. 1989.

[3] Callejo, M. L. Un club matemático para la diversidad. Narcea, Madrid. 1998.

[4] Carrillo, J. Creencias sobre la resolución de problemas. Modos de resolver problemas y concepciones sobre la matemática y su enseñanza de profesores de matemáticas de alumnos de más de 14 años. Algunas aportaciones a la metodología de la investigación y estudio de posibles relaciones. Tesis doctoral. Universidad de Sevilla. 1996.

[5] Deulofeu, J., Mallart, A. "Una estrategia para mejorar la comprensión de los enunciados de los problemas". Revista Uno. Revista de Didáctica de las matemáticas, (2012), 59, 83-92.

[6] Díaz Rodríguez, J.J. Guía para elaboración de unidades didácticas. Enseñanza Secundaria. Consejería de Educación y Ciencia, Jaén. 1993. 
[7] Eisner, W. El cómic y el arte secuencial. Norma Editorial, Barcelona. 1996.

[8] Flores, P. Humor gráfico en el aula de matemáticas. Arial, Granada. 2003.

[9] Flores, P., Moreno, A. J. Matemáticamente competentes? para reír. Grao, Barcelona. 2011.

[10] Historia del cómic. En https://www . youtube.com/watch?v=Mm6P_q33lvs (consultada el 18 de octubre, 2016).

[11] Intercambio de monografías: El Cómic. En http://www.uclm.es/profesorado/ricardo/comic2. html (consultada el 18 de octubre, 2016).

[12] León, N. "Creando, dibujando... aprendiendo matemática a través del cómic". Cuadernos de Investigación y Formación en Educación Matemática, (2014), 12, 111-123.

[13] Lozano, A. "Factores personales, familiares y académicos que afectan al fracaso escolar en le Educación Secundaria". Revista Electrónica de Investigación Psicoeducativa y Psicopedagógica, (2003), $1(1), 43-66$.

[14] Marrero, M. "Lengua y matemáticas EL CÓMIC" En https://www.youtube.com/watch?v=SIe5Tj37yE (consultada el 18 de octubre, 2016).

[15] Pixton.com. En http://www.pixton.com/mx/ (consultada el 18 de octubre, 2016).

[16] Puig, L. Elementos de resolución de problemas. Comares, Granada. 1996.

[17] Shirmahaleh, Shekoufeh. Iconicidad metafórica de Charles S. Peirce, aspectos teóricos y aplicaciones ling uísticas. Tesis doctoral. Universidad de Alicante. 2010

[18] Tahan, M. El hombre que calculaba. Verón, Barcelona. 2007.

[19] Vila, A. Resolució de problemas de matemátiques: identificació, origen i formació dels sistemes de creences en l'alumnat. Alguns efectes sobre l' abordatge del problemas. Tesis doctoral. Universidad Autónoma de Barcelona. 2001. 